\title{
She could no longer wear a hat: Paget's disease
}

\author{
José Miguel Maia, Rute Alves, Raquel Faria, Fátima Farinha
}

Department of Internal Medicine, Centro Hospitalar Porto, Porto, Portugal

\section{Correspondence to} Dr José Miguel Maia, zemiguelmaia@gmail.com

Accepted 30 October 2014

\section{DESCRIPTION}

In the 1980 s, a woman in her 40s started noticing that her hats were not fitting. She also reported suffering from headache, hearing loss and tinnitus. Alkaline phosphatase and urinary hydroxyproline levels were raised in the beginning. She was diagnosed with Paget's disease.

She was started on calcitonin treatment and when available, a few years later, bisphosphonates. ${ }^{1}$

Paget's disease is a localised disorder of bone remodelling that typically begins with excessive bone resorption followed by an increase in bone formation. This leads to a structurally disorganised mosaic of bone, which is mechanically weaker, larger, less compact, more vascular and more susceptible to fracture.

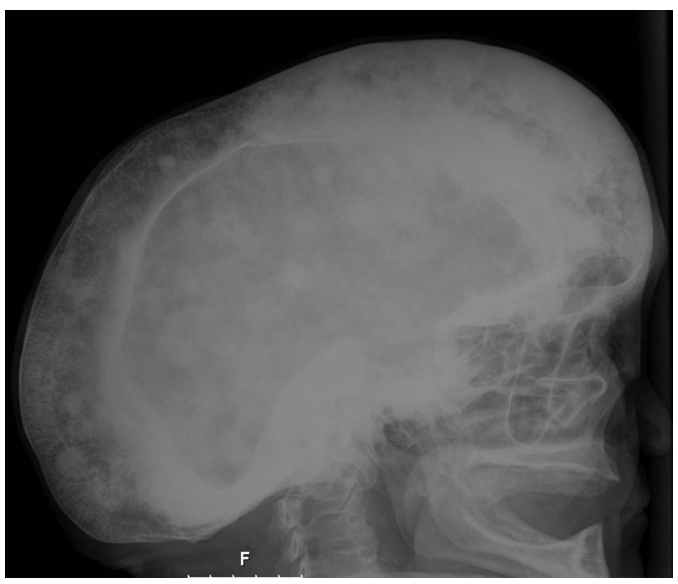

Figure 1 Lateral view: enlarged skull with severe thickening of the inner and outer table, leading to diploid widening; multiple lytic and sclerotic lesions in the thickened calvarium ('cotton wool' appearance) ${ }^{2}$ and sclerosis of the skull base.
After three decades, the skull bones grew as seen in figures 1 and 2 .

This case report shows the evolution of the disease for more than 30 years, despite the available treatment at times. Over a period of time, the disease remained monostotic (figure 3).

Paget's disease may involve a single bone but is more frequently multifocal with a predilection for the axial skeleton; however, any bone may be affected.

After onset, Paget's disease does not spread from bone to bone, but it may become progressively worse at pre-existing sites.

Currently, there are no signs of activity of the disease.

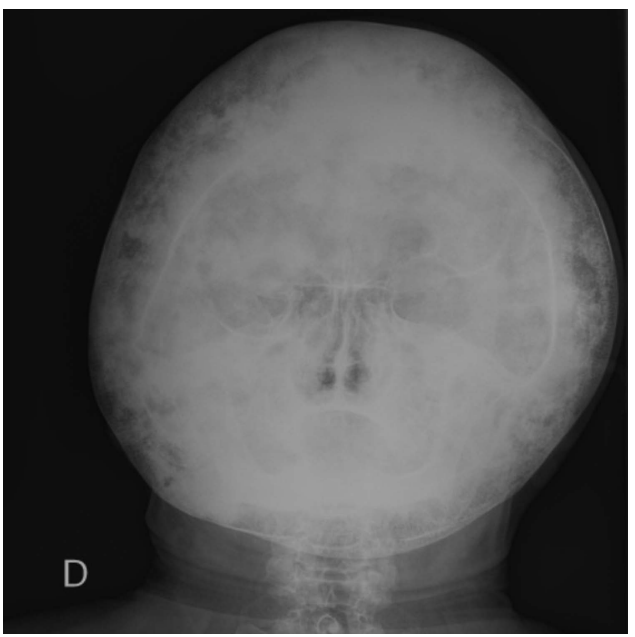

Figure 2 Frontal view: enlarged skull with severe thickening of the inner and outer table, leading to diploid widening; multiple lytic and sclerotic lesions in the thickened calvarium ('cotton wool' appearance) ${ }^{2}$ and sclerosis of the skull base. 

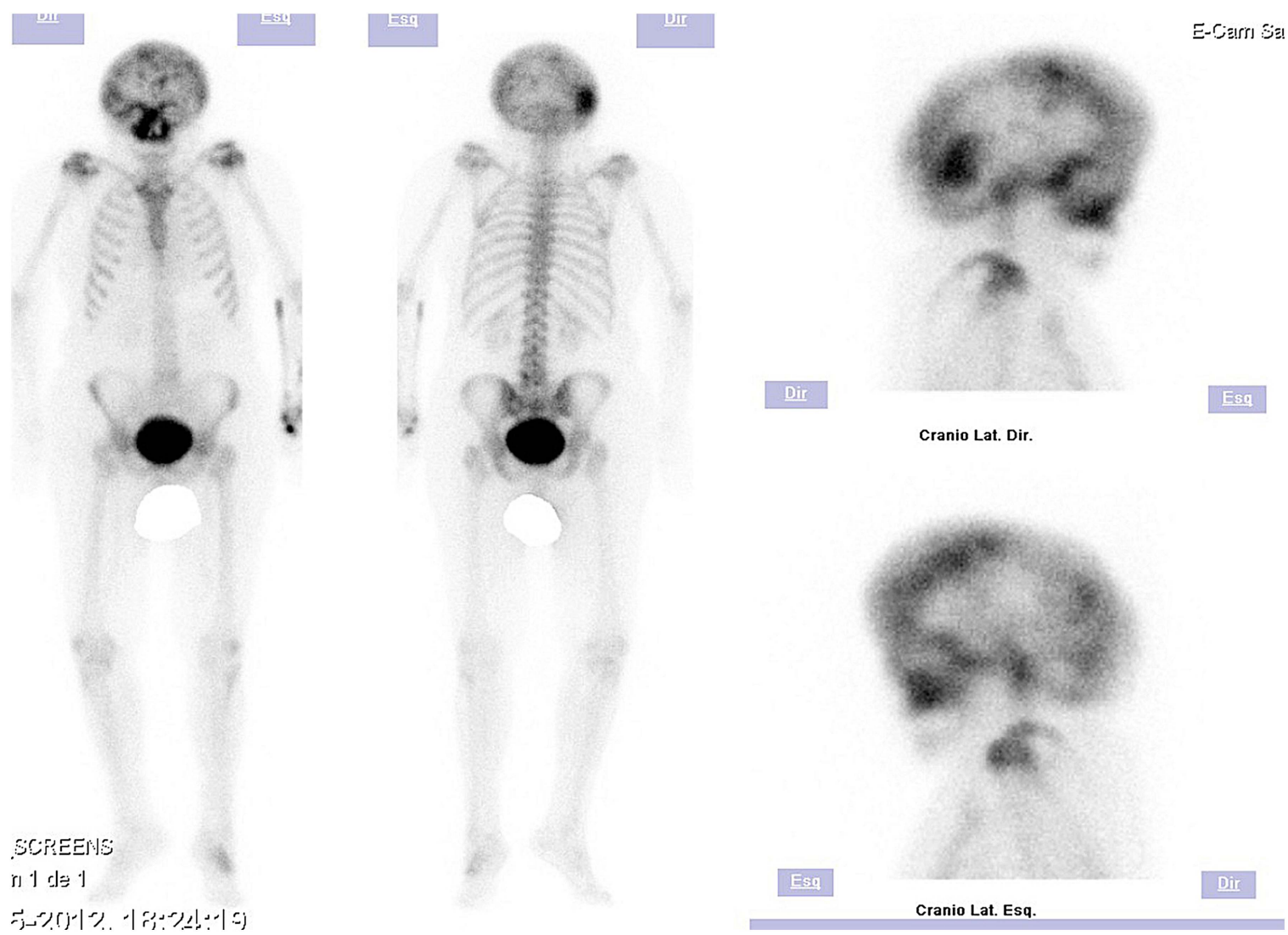

Figure 3 Heterogeneous fixation in the skull, predominantly at the right occipitoparietal region and facial bones.

\section{Learning points}

- Although rare, headaches associated with hearing loss, enlargement or bowing of bones, tingling or numbness should lead one to suspect Paget's disease. ${ }^{1}$

- It is a chronic condition, focused on one or a few bones of the pelvis, back (spine), hips, thighs, head and arms, ${ }^{1}$ but rarely polyostotic.

- Bisphosphonates are the first line of treatment for localised pain, which is thought to be due to increased bone metabolic activity and consequent increased circulation. ${ }^{1}$

- Follow-up should focus on activity and complications: fractures, nervous system involvement or nerve entrapment, osteoarthritis or a coexisting musculoskeletal condition. ${ }^{1}$
Competing interests None.

Patient consent Obtained.

Provenance and peer review Not commissioned; externally peer reviewed.

\section{REFERENCES}

1 Ralston SH. Paget's disease of bone. N Engl J Med 2013;368:644-50.

2 Daphne JT, Stavroula JT, Yousuke K. Imaging of Paget disease of bone and its musculoskeletal complications: review. AJR 2011;196:S64-75.

Copyright 2014 BMJ Publishing Group. All rights reserved. For permission to reuse any of this content visit http://group.bmj.com/group/rights-licensing/permissions.

BMJ Case Report Fellows may re-use this article for personal use and teaching without any further permission.

Become a Fellow of BMJ Case Reports today and you can:

- Submit as many cases as you like

- Enjoy fast sympathetic peer review and rapid publication of accepted articles

- Access all the published articles

- Re-use any of the published material for personal use and teaching without further permission

For information on Institutional Fellowships contact consortiasales@bmjgroup.com

Visit casereports.bmj.com for more articles like this and to become a Fellow 